\title{
Resource implications of patients with multidrug resistant tuberculosis
}

\author{
V L C White, J Moore-Gillon
}

\begin{abstract}
Background-Multidrug resistant tuberculosis (MDR TB) requires a complex drug regimen and lengthy multidisciplinary care. The financial cost of successful management of each case is potentially large.

Methods-The costs of managing nine HIV negative patients with pulmonary MDR TB were compared with 18 age group and ethnicity matched controls with fully sensitive disease. Calculations included: cost of outpatient visits and inpatient stays including negative pressure isolation; costs of drug provision and toxicity monitoring; costs of additional procedures and multidisciplinary referrals.

Results-The mean cost of managing a case of pulmonary MDR TB was in excess of $£ 60000$ and for sensitive disease it was $£ 6040$.

Conclusions-Clinicians and healthcare commissioning authorities may both be underestimating the costs of managing MDR TB, and accordingly the consequences for units dealing with such cases may be serious. Funding of care for MDR $T B$ in the UK requires strategic decisions at regional or governmental level.

(Thorax 2000;55:962-963)
\end{abstract}

Keywords: tuberculosis; multidrug resistance; healthcare resources

Department of

Respiratory Medicine,

Bart's and the London

NHS Trust, $\mathbf{S t}$

Bartholomew's

Hospital, London

EC1A 7BE, UK

V L C White

J Moore-Gillon

Correspondence to: Dr V L C White

vlcw@btinternet.com

Received 5 January 2000 Returned to authors 29 March 2000

Revised version received

30 June 2000

Accepted for publication

28 July 2000
Multidrug resistant tuberculosis (MDR TB) is defined as resistance to rifampicin and isoniazid, with or without resistance to other antituberculous drugs. ${ }^{12}$ Cases are uncommon in the UK as a whole (51 reported cases in the UK in 1998) but are geographically concentrated in urban areas, and specifically in London with 23 cases in 1998.

The management of MDR TB comprises far more than the use of complex second and third line antituberculous drug regimens. Patients with the disease often need to spend prolonged periods in hospital negative pressure rooms with specialist nursing care, multidisciplinary medical input, and extensive use of laboratory services. $^{24}$
We have investigated the resources involved in treating such individuals in our hospital group.

\section{Methods}

We analysed the pattern of care in nine HIV negative patients with pulmonary MDR TB treated in our hospital group between 1996 and 1999 and compared it with 18 age and ethnicity matched patients selected at random from our local TB notifications database. We recorded drug regimens, duration and length of inpatient hospital stay, and the number of outpatient appointments. We also examined the "extra" costs incurred by the requirements of additional therapeutic drug monitoring, the provision of negative pressure facilities, additional nursing costs, and referrals to other specialities, including surgical intervention.

Specific drug costs for each individual regimen were calculated from NHS basic cost figures as adjusted by the hospital pharmacy to take account of local purchasing. ${ }^{5}{ }^{6}$ Mean costs of one medical inpatient day with overheads and of an outpatient visit for the respiratory medicine service were provided by the Trust finance and contracts departments. The capital provision and maintenance costs of negative pressure isolation rooms were calculated by the Trust estates department from actual spending figures and national building norms. ${ }^{7}$ Additional nursing costs for negative pressure rooms were derived from the Trust's department of nursing and quality assurance ward establishment figures. Therapeutic drug monitoring costs were provided by the Trust's microbiology department.

Table 1 Cost of drugs used in the treatment of tuberculosis

\begin{tabular}{ll}
\hline Drug and daily dose & Annual cost $(£)$ \\
\hline Amikacin $1 \mathrm{~g}$ & $£ 6430$ \\
Capreomycin $1 \mathrm{~g}$ & $£ 6580$ \\
Ciprofloxacin $1 \mathrm{~g}$ & $£ 980$ \\
Clarithromycin $1 \mathrm{~g}$ & $£ 1040$ \\
Clofazamine $300 \mathrm{mg}$ & $£ 76$ \\
Cycloserine $500 \mathrm{mg}$ & $£ 1685$ \\
Ethambutol $1 \mathrm{~g}$ & $£ 356$ \\
Isoniazid $300 \mathrm{mg}$ & $£ 26$ \\
PAS 7.4 g & $£ 5190$ \\
Prothionamide $750 \mathrm{mg}$ & $£ 880$ \\
Pyrazinamide $2 \mathrm{~g}$ & $£ 110$ \\
Rifabutin $900 \mathrm{mg}$ & $£ 3140$ \\
Rifampicin $600 \mathrm{mg}$ & $£ 85$ \\
Streptomycin $1 \mathrm{~g}$ & $£ 2450$ \\
\hline
\end{tabular}


Table 2 Sample costs for therapeutic drug monitoring

\begin{tabular}{ll}
\hline Streptomycin & $£ 43.56$ \\
Amikacin $^{\star}$ & $£ 27.54$ \\
Cycloserine $^{\star}$ & $£ 74.84$ \\
Rifampicin & $£ 74.84$ \\
Ethambutol & $£ 22.00$ \\
Pyrazinamide† & $£ 22.00$ \\
\hline
\end{tabular}

^Charge for a single or paired specimen (pre and post dose level).

†Charge for a single sample only.

Table 3 Cost data for individual patients with MDR TB

\begin{tabular}{lcll}
\hline Patients & $\begin{array}{c}\text { Inpatient } \\
\text { (days) }\end{array}$ & $\begin{array}{l}\text { Outpatient } \\
\text { appointments }\end{array}$ & Drug costs $(f)$ \\
\hline MDR1 & 54 & 55 & 16675 \\
MDR2 & 110 & 20 & 19915 \\
MDR3 & 0 & 32 & 11700 \\
MDR4 & 274 & 9 & 17385 \\
MDR5† & 26 & 25 & 4765 \\
MDR6 & 17 & 6 & 7460 \\
MDR7 & 33 & 6 & 8180 \\
MDR8 & 174 & 13 & 10075 \\
MDR9 & 11 & 20 & 1315 \\
Controls 1-18 & & & $150(80-765)$ \\
mean (range) & $10(0-58)$ & $8(4-25)$ & \\
\hline
\end{tabular}

All costs are adjusted to 2000 prices.

${ }^{\star}$ Currently on treatment; drug cost projected for two years of treatment.

†Died of other causes on treatment; cost calculated to death.

\section{Results}

Our hospital group calculates the mean costs of one inpatient day with overheads at $£ 535$, and an outpatient visit for our respiratory medicine service is calculated at $£ 67$. The price of one year of treatment with some of the drugs used in this group of patients and of antituberculous drug monitoring is listed in tables 1 and 2, respectively. Cost data for each individual patient with MDR TB are shown in table 3, and group data for the sensitive cases are summarised there.

Even calculated on this "standard hospital cost" basis, the mean cost of treating a patient with MDR TB was $£ 54000$ compared with $£ 6040$ for fully sensitive disease, but this MDR TB figure is a substantial underestimate of the true cost, taking no account of the numerous factors which make managing such patients more expensive than an "average" hospital patient.

The capital cost of building negative pressure rooms within a pre-existing hospital infrastructure is $£ 40000$ per room with a life expectancy of 10-15 years; the maintenance of such a room is approximately $£ 1000$ per year, adding an extra $£ 15$ per inpatient day. Nursing costs are $50 \%$ higher than those on a standard ward and add an additional $£ 50$ per bed day. Two patients underwent thoracic surgery costing $£ 2300$ per patient additional to these enhanced inpatient and nursing costs. In the MDR TB group additional therapeutic drug monitoring cost a mean of $£ 200$.

These additional costs per patient bring the total up from the basic mean of $£ 54000$ to $£ 60000$ (range $£ 9600-£ 184000$ ).

\section{Discussion}

The mean cost of managing a patient with pulmonary MDR TB was calculated to be f60 000. This, however, is itself an underestimate. The above calculations of the additional capital and running costs for isolation rooms are valid only with an assumed $100 \%$ bed occupancy throughout the lifetime of the room, and similar arguments apply to the additional nursing costs. Further, there is increased multidisciplinary professional time involved in meeting the medical, nutritional, psychological, and physical fitness needs of patients confined to a room-sometimes for months on end-and increased pharmacy time spent in sourcing and supplying unusual drugs.

We excluded from this study those patients with co-existent known HIV infection, and those with non-pulmonary MDR TB. Accordingly, we have not included patients who may have been referred to our hospital trust from outside our local population because of its specialist services such as neurosurgery and its large unit for those with HIV infection. We believe our findings are likely to be broadly applicable to cases of pulmonary MDR TB presenting to colleagues elsewhere.

Our findings thus have important resource implications for hospitals treating even a single patient with MDR TB, and indicate potentially profound consequences for centres dealing with numerous cases. It is likely that purchasers and commissioning authorities are, like clinicians, underestimating the true costs of managing such individuals. Funding of care for MDR $\mathrm{TB}$ in the UK may require strategic decisions at regional or Department of Health level.

We are indebted to colleagues from many disciplines within our hospital trust for their advice and information. In particular we thank Mr Roger Tuke and $\mathrm{Mr}$ Ernie Wallace (Facilities Directorate), Dr Satya Das (Consultant Microbiologist), Ms Sarah Blakey (Head Nurse, Medical Directorate) and Ms Ama Appiah and Mr Nigel Brinklow (Pharmacy). VW and JMG jointly conceived the study. VW collected and collated the data which was discussed and checked with JMG. VW and JMG jointly wrote the paper.

Funding: Dr White is currently funded by the Joint Research Board of St Bartholomew's Hospital.

Conflict of interest: none.

1 Iseman MD. Treatment of multidrug resistant tuberculosis. N Engl F Med 1993;329:784-91.

2 Joint Tuberculosis Committee of the British Thoracic Society. Chemotherapy and management of tuberculosis in the United Kingdom: recommendations 1998. Thorax 1998; 53:536-48

3 Public Health Laboratory Service. Mycobnet: UK Mycobacterial Resistance Network Database. February 2000 (www. phls.co.uk)

4 Interdepartmental Working Group on Tuberculosis. The prevention and control of tuberculosis in the United Kingdom. UK guidance on the prevention and control of transmission of 1 . HIV related tuberculosis; 2. Drug-resistant, including multiple drug resistant tuberculosis. Department of Health, Scottish Office, Welsh Office: September 1998

5 British National Formulary. London: British Medical Association and Royal Pharmaceutical Society of Great Britain, March 2000.

6 Monthly Index of Medical Specialities. London: Haymarket, March 2000.

7 Davies Langdon \& Everest, Chartered Quantity Surveyors, eds. Spon's architects' and builders'price book. 125th ed. London, E \& FN Spon, 2000. 